\title{
EXPERIMENTAL STUDY ON DRYING SHRINKAGE OF STRUCTURAL LIGHTWEIGHT CONCRETE USING FLY ASH CENOSPHERES
}

\author{
Le Viet Hung ${ }^{1}$, Le Trung Thanh ${ }^{1}$ and Nguyen Van Tuan²* \\ ${ }^{1}$ Vietnam Institute for Building Materials, 235 Nguyen Trai, Thanh Xuan district, Hanoi, Vietnam. \\ ${ }^{2}$ Faculty of Building Materials, Hanoi University of Civil Engineering, 55 Giai Phong, Hai Ba Trung district, \\ Hanoi, Vietnam.
}

*Corresponding Author, Received: 21 Sept. 2021, Revised: 17 Oct. 2021, Accepted: 21 Nov. 2021

\begin{abstract}
This paper presents an experimental investigation of drying shrinkage of high-strength lightweight concrete (HSLWC) using fly ash cenospheres (FAC) as an aggregate to substitute fine sand with a designed density from 1200 to $1700 \mathrm{~kg} / \mathrm{m}^{3}$ and a desired compressive strength from 30 to $80 \mathrm{MPa}$. Drying shrinkage for six months of FAC HSLWC was investigated considering the effect of various factors. These factors include the fine sand replacement with FAC contents of $0,20,30,40 \%$ by vol. of the concrete mixture, the binder content of 750 to $950 \mathrm{~kg} / \mathrm{m}^{3}$, the water to binder ratio of 0.35 to 0.6 , the shrinkage reducing admixture (SRA) content of $0,2,3 \% \mathrm{wt}$. of binder, and the polypropylene fiber (PP) content of $0,0.3$, and $0.5 \%$ by vol. of the concrete mixture. The experimental results show that the incorporation of FAC content compensated drying shrinkage of HSLWC, and the 182-day drying shrinkage of FAC HSLWC was lower than that of the reference sample without FAC. Besides, the addition of SRA and PP fiber was found effective in reducing the shrinkage of FAC HSLWC.
\end{abstract}

Keywords: Shrinkage, Drying shrinkage, Cenospheres, Lightweight aggregate, High-strength lightweight concrete.

\section{INTRODUCTION}

In the modern construction industry, the market size of high-rise building construction has rapidly increased. This leads to a significant challenge in the research and use of lightweight concrete structures with similar strength and durability to conventional concrete ones to reduce building loads, increase sound insulation, heat insulation, ease transportation, construction, installation, etc.

For lightweight aggregate concrete used for loadbearing structures in construction, it is required minimum compressive strength of $17 \mathrm{MPa}$, but the practical value of 21-35 MPa is commonly used (ACI 213-14 [1]). Some building structures such as high-rise buildings, bridges normally require highstrength lightweight concrete (HSLWC) with compressive strength not lower than $40 \mathrm{MPa}$ and a density ranging of $1680-1920 \mathrm{~kg} / \mathrm{m}^{3}$ to replace concrete with a compressive strength of 50-60 MPa [1]. Regarding the raw materials of HSLWC, artificial lightweight aggregates (LWA) made from expanded clay, shale, and slate with a particle size range from fine to coarse are commonly used. This exhibits some disadvantage properties such as high porosity and water absorption (normally 20-25\%) due to the sizeable porous structure of LWAs. These properties result in fluctuating density and volume stability when being exposed to humid or wet environments, as well as durability and corrosion protection for reinforcement of concrete, especially for structures exposed to aggressive environments. Fly ash cenospheres (FAC) are hollow spherical particles with a low density of $0.4-0.9 \mathrm{~g} / \mathrm{cm}^{3}$ derived from fly ash of coal burnt thermal power plants. The particle size of FAC is commonly in the range of 1 to $400 \mu \mathrm{m}$ with predominant sizes of $20-300 \mu \mathrm{m}$. Thus, FAC particles are more extensive than common fly ash ones with a predominant particle size below $20 \mu \mathrm{m}$ [2, 3]. Besides, FACs exhibit a high crushing strength, typically from 15.5 to 17.6 MPa [4], good air and water impermeability [5]. Based on these advantages, studies on using FAC as a lightweight filler to produce HSLWC have received attention over the past decades with potential applications, e.g. for reinforced concrete and sandwich concrete structures [6].

One of the first attempts of using FACs in cementitious systems was conducted by Montgomery and Diamond [7] in 1984. Later on, the use of FAC as lightweight aggregates for lightweight concrete was firstly studied by Losiewicz M. [8]. However, although the lightweight concrete with low density was achieved but the low strength was still an unsolved issue. The concrete was therefore mainly applied for insulation. At the beginning of the $21^{\text {st }}$ century, studies on improving the strength of LWC using FAC were conducted, and HSLWC with many 
properties superior to the traditional aggregate lightweight concrete was produced. Blanco [9] produced an LWC using FAC with a 28-day compressive strength of 27-33 MPa and density of $1387-1510 \mathrm{~kg} / \mathrm{m}^{3}$. Besides, Huang, et al. [10] also demonstrated that LWC using iron ore tails, fly ash, and FAC with a 28-day compressive strength of 25$47.6 \mathrm{MPa}$ and density of $1649-1820 \mathrm{~kg} / \mathrm{m}^{3}$ can be fabricated. Furthermore, [11] successfully demonstrated in producing lightweight concrete called ultra-lightweight concrete (ULWC) with a density of 1154-1471 $\mathrm{kg} / \mathrm{m}^{3}$ and 28-day compressive strength in a range of 33.0-69.4 MPa, a flexural strength of $8 \mathrm{MPa}$, and thermal conductivity mainly from 0.3 to $0.8 \mathrm{~W} / \mathrm{m}$.K, which is much lower than that of ordinary concrete with this regular property of about $1.9 \mathrm{~W} / \mathrm{m} . \mathrm{K}$.

In general, studies on LWC using FAC mainly focus on mechanical properties and thermal insulation and their relationship with density. Very few studies investigating the shrinkage of HSLWA using FAC (FAC HSLWC) have been published up to now. In fact, concrete shrinkage is an important parameter in the design of concrete structures regarding the cracking resistance of concrete caused by stresses developed in concrete structures due to the restraining volume change. Concrete structures with cracks formed will significantly influence on the long-term durability of concrete when being exposed to aggressive environments. The shrinkage of concrete is highly dependent on the cement paste volume (or binder content), type and amount of aggregate, and water-to-cement (or binder) ratio.

It should be noted that most FAC HSLWC do not contain coarse aggregates and even no fine aggregate at a sand-size level. Therefore, the shrinkage of HSLWC has been found to be higher than that of conventional concrete using coarse aggregate and lightweight aggregate from expanded clay [12]. This can be compensated by using expansion additives, shrinkage-reducing admixtures, or a combination [11, 12]. Besides using polypropylene fiber, PVA fiber was also demonstrated effectively to reduce shrinkage and cracks for concrete [13-15]. Meanwhile, some studies showed the opposite results; for example, Aly, et al. [14] found that using PP fibers increased the total shrinkage of concrete with 0.05 to $0.5 \%$ PP fibers (by vol.). Hence, more research investigation should be implemented to evaluate this scientific point.

This paper focuses on the drying shrinkage of FAC HSLWC, in which some influencing factors such as FAC content, fine aggregate content, shrinkagereducing admixture, and polypropylene fibers were considered. All shrinkage results of this LWC were compared to those of normal concrete with the same strength.

\section{EXPERIMENTAL PROGRAM}

\subsection{Materials}

Ordinary Portland cement (OPC) type PC50 (Vietnamese standard TCVN 2682), undensified silica fume (SF) from Elkem, FAC, river sand (RS) with a particle size of $0.15-0.63 \mathrm{~mm}$ were used in this study. Their properties are presented in Table 1, and particle size distribution is shown in Fig. 1. A shrinkage reducing admixture from SilkRoad was used. Polypropylene fibers in the form of collated fibrillated fiber bundles with 12-20 mm length, the density of $0.91 \mathrm{~g} / \mathrm{cm}^{3}$, the tensile strength of 450 $\mathrm{MPa}$, the elastic modulus of $3500 \mathrm{MPa}$ was also used in this study.

Table 1 Physical properties of cement, silica fume,

\begin{tabular}{ccccc}
\multicolumn{5}{c}{ FAC and sand } \\
\hline Properties & OPC & SF & FAC & Sand \\
\hline $\begin{array}{c}\text { Density, g/cm }{ }^{3} \\
\text { Water }\end{array}$ & 3.05 & 2.15 & 0.78 & 2.62 \\
absorption, \% & - & - & 10.3 & 3.2 \\
Setting time, min. & & & & \\
$\quad$ Initial & 120 & - & - & - \\
$\quad$ Final & 195 & & & \\
Specific surface & 382 & 29900 & - & - \\
area, cm ${ }^{2} / g$ & 0 & & & \\
Mean particle & 16.68 & 0.15 & 116 & 225 \\
size, $\mu \mathrm{m}$ & & & & \\
Compressive & & & & \\
strength, MPa & & - & - & - \\
3 days & 33.6 & & & \\
28 days & 53.5 & & & \\
\hline
\end{tabular}

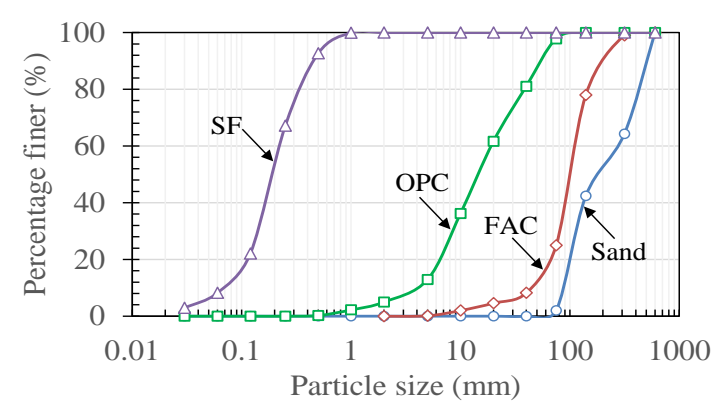

Fig. 1 Particle size distribution of raw materials

\subsection{Test Methods}

Workability of FAC HSLWC mixtures was determined by flow table according to BS EN 10153:1999. Compressive strength and oven drying density of FAC HSLWC was determined on prismatic specimens with a size of $40 \times 40 \times 160 \mathrm{~mm}$ as per BS EN 196-1:2016 and BS EN 1015-10:1999, respectively. Dry shrinkage was measured on prismatic specimens with a size of $75 \times 75 \times 280 \mathrm{~mm}$ 
Table 2 Mix proportions of FAC HSLWC

\begin{tabular}{|c|c|c|c|c|c|c|c|c|c|}
\hline \multirow[b]{2}{*}{ Mix } & \multirow{2}{*}{$\begin{array}{c}\text { FAC } \\
\text { content } \\
\text { (vol.\% of } \\
\text { mixture) }\end{array}$} & \multirow{2}{*}{$\begin{array}{c}\text { RS/ } \\
\text { FAC ratio } \\
\text { (\% by vol.) }\end{array}$} & \multirow{2}{*}{$\begin{array}{c}\mathrm{FAC/} \\
\text { (RS+FAC) } \\
\text { ratio (vol.\%) }\end{array}$} & \multirow[b]{2}{*}{$\begin{array}{l}\text { W/B ratio } \\
\text { (by wt.) }\end{array}$} & \multirow{2}{*}{$\begin{array}{l}\text { Binder } \\
\text { content } \\
\left(\mathrm{kg} / \mathrm{m}^{3}\right)\end{array}$} & \multicolumn{2}{|c|}{ Binder mixture } & \multicolumn{2}{|c|}{ Addition } \\
\hline & & & & & & $\begin{array}{c}\text { OPC } \\
\text { (wt.\%) }\end{array}$ & SF (wt.\%) & $\begin{array}{l}\text { SRA (wt.\% } \\
\text { of binder) }\end{array}$ & $\begin{array}{c}\text { PP fiber (vol.\% } \\
\text { of } \\
\text { mixture) }\end{array}$ \\
\hline $\begin{array}{l}\text { FAC0W0.4 } \\
\text { (Reference) }\end{array}$ & 0 & - & 0 & 0.4 & 750 & 90 & 10 & 0 & - \\
\hline FAC40W0.6 & 40 & 0 & 100 & 0.6 & 750 & 90 & 10 & 0 & 0 \\
\hline FAC40W0.5 & 40 & 0 & 100 & 0.5 & 750 & 90 & 10 & 0 & 0 \\
\hline FAC40W0.35 & 40 & 0 & 100 & 0.35 & 750 & 90 & 10 & 0 & 0 \\
\hline FAC40W0.4 & 40 & 0 & 100 & 0.4 & 750 & 90 & 10 & 0 & 0 \\
\hline FAC30W0.4 & 30 & 40 & 71 & 0.4 & 750 & 90 & 10 & 0 & 0 \\
\hline FAC20W0.4 & 20 & 100 & 50 & 0.4 & 750 & 90 & 10 & 0 & 0 \\
\hline FAC40SRA2.0 & 40 & 0 & 100 & 0.4 & 750 & 90 & 10 & 2.0 & 0 \\
\hline FAC40SRA3.0 & 40 & 0 & 100 & 0.4 & 750 & 90 & 10 & 3.0 & 0 \\
\hline FAC40PP0.3 & 40 & 0 & 100 & 0.4 & 750 & 90 & 10 & 0 & 0.30 \\
\hline FAC40PP0.5 & 40 & 0 & 100 & 0.4 & 750 & 90 & 10 & 0 & 0.50 \\
\hline FAC40B850 & 40 & 0 & 100 & 0.4 & 850 & 90 & 10 & 0 & 0 \\
\hline FAC40B950 & 40 & 0 & 100 & 0.4 & 950 & 90 & 10 & 0 & 0 \\
\hline
\end{tabular}

and test procedures according to BS ISO 19208:2011 with modification of curing condition for suitable that specified in Vietnamese standard.

After casting and curing under standard curing for $24 \mathrm{~h}$, specimens were demoulded and immersed in water until 7 days from moulding, then taken to measure the initial length of the specimens.

After that, specimens were cured in a climate cabinet-controlled condition of $27 \pm 1{ }^{\circ} \mathrm{C}, 55 \pm 5 \%$ $\mathrm{RH}$. Subsequent length measurements were taken after periods of this dry curing condition of 7,14 , 28, 91, 182 days.

\subsection{Mix Proportion}

Binder (cementitious materials) hereby were a mixture of OPC and SF in which SF was fixed at 10 wt.\% of the binder. The evaluation of FAC HSLWC properties was carried out with mixes using different FAC volume fractions of $0,20,30$, and $40 \%$ obtained by replacing sand by FAC at FAC-to(RS+FAC) ratios of $0 \%, 50 \%, 71 \%$, and $100 \%$ by vol.; the water-to-binder (W/B) ratios varied from 0.35 to 0.6 ; binder contents varied from 750 to 950 $\mathrm{kg} / \mathrm{m}^{3}$; SRA contents of $0,2,3 \mathrm{wt} . \%$ by the binder; and PP fiber contents of $0,0.3$ and $0.5 \%$ by vol. of the mixes. Details of mix proportions of FAC HSLWC are presented in Error! Reference source not found..

\subsection{Mixing Procedure}

A 5-liter Hobart mixer was used to make the mixtures. The process of mixing materials was as follows: all dry materials, including sand, FAC, OPC, and SF were mixed for 2 minutes, then about $70 \%$ water was added and further mixing for 2 minutes. After that, the solution of superplasticizer and $30 \%$ remaining water was added and well mixed for 2-3 minutes. The superplasticizer dosage was adjusted to attain workability, i.e. the flow table values between 160 and $180 \mathrm{~mm}$.

\section{RESULTS AND DISCUSSIONS}

\subsection{Effect of FAC and Sand Content on Density,} Compressive Strength, and Drying Shrinkage

Table 3 shows the experimental results of density, compressive strength, and drying shrinkage of FAC HSLWC mixtures with different densities from 1284 to $1708 \mathrm{~kg} / \mathrm{m}^{3}$. Obviously, the addition of FAC decreases specimens' density and compressive strength due to its very low density. For example, the density of specimens incorporating $0,20,30$ to $40 \%$ FAC with W/B ratio of 0.40 decreases to $2180,1708,1580,1367 \mathrm{~kg} / \mathrm{m}^{3}$, respectively. Similarly, the corresponding 28-day compressive strength of FAC HSLWC decreases to 74.1, 72.7, 69.8, 67.2 MPa.

Experimental results of drying shrinkage of FAC HSLWC as presented in Fig. 2 show that drying shrinkage of concrete tends to decrease with the addition of FAC. The 182-day drying shrinkage of concrete decreases 3,8 , and $26 \%$, respectively, compared to the reference sample. Note that in the absence of coarse aggregate, a high binder content 
Table 3 Density, strength, and drying shrinkage of HSLWC with and without FAC

\begin{tabular}{|c|c|c|c|c|c|c|c|c|}
\hline \multirow{2}{*}{ Mix } & \multirow{2}{*}{$\begin{array}{l}\text { 28-day density } \\
\left(\mathrm{kg} / \mathrm{m}^{3}\right)\end{array}$} & \multirow{2}{*}{$\begin{array}{c}\text { 28-day } \\
\text { compressive } \\
\text { strength }(\mathrm{MPa})\end{array}$} & \multicolumn{6}{|c|}{ Drying shrinkage $(\mu \varepsilon)$ after dry curing duration (days) } \\
\hline & & & 0 & 7 & 14 & 28 & 91 & 182 \\
\hline $\begin{array}{l}\text { FAC0W0.4 } \\
\text { (Reference) }\end{array}$ & 2180 & 74.1 & 0 & 490 & 650 & 790 & 916 & 1120 \\
\hline FAC40W0.6 & 1284 & 38.9 & 0 & 707 & 977 & 1242 & 1865 & 2298 \\
\hline FAC40W0.5 & 1342 & 56.5 & 0 & 490 & 560 & 707 & 935 & 1107 \\
\hline FAC40W0.35 & 1422 & 71.4 & 0 & 320 & 408 & 554 & 650 & 756 \\
\hline FAC40W0.4 & 1367 & 67.2 & 0 & 300 & 518 & 647 & 788 & 940 \\
\hline FAC30W0.4 & 1580 & 69.8 & 0 & 454 & 640 & 768 & 898 & 1033 \\
\hline FAC20W0.4 & 1708 & 72.7 & 0 & 470 & 660 & 802 & 912 & 1090 \\
\hline FAC40SRA2.0 & 1376 & 71.3 & 0 & 260 & 400 & 520 & 632 & 792 \\
\hline FAC40SRA3.0 & 1382 & 74.6 & 0 & 233 & 347 & 495 & 600 & 754 \\
\hline FAC40PP0.3 & 1354 & 68.6 & 0 & 350 & 430 & 620 & 830 & 900 \\
\hline FAC40PР0.5 & 1342 & 67.5 & 0 & 230 & 367 & 526 & 780 & 872 \\
\hline FAC40B850 & 1393 & 71.4 & 0 & 330 & 530 & 660 & 809 & 962 \\
\hline FAC40B950 & 1414 & 75.2 & 0 & 360 & 540 & 686 & 840 & 986 \\
\hline
\end{tabular}

$\left(750 \mathrm{~kg} / \mathrm{m}^{3}\right)$ with a total volume of binder paste is 525 liters $/ \mathrm{m}^{3}(\mathrm{~W} / \mathrm{B}=0.4)$ results in a high drying shrinkage $(1120 \mu \varepsilon)$ of the reference sample.

The partial or full replacement of sand by FAC has improved drying shrinkage compared with the reference sample using 100\% sand (FAC0W40). However, only the sample containing 40\% FAC (FAC40W40) achieved a drying shrinkage of less than $1000 \mu \varepsilon$ after 182 days of dry curing. In addition, it can be realized that the drying shrinkage of FAC HSLWC exhibits a higher value than the typical drying shrinkage of conventional concrete (with both coarse and fine concrete) normally reported in a range of $200-800 \mu \mathrm{m}(\mathrm{W} / \mathrm{B}=0.4)$ in the literature [16].

The phenomenon of a decrease in the drying shrinkage of concrete when using FAC partially replaced for sand with the same volume fraction of (RS+FAC) can be explained by the fact that FAC particles in concrete not only act as micro-aggregates similar to fly ash particles. It means that FAC can react with $\mathrm{Ca}(\mathrm{OH})_{2}(\mathrm{CH})$ generated from cement hydration to produce calcium silicate hydrate (C-S$\mathrm{H})$ products that make a denser microstructure of the binder matrix of concrete $[3,17]$. This contributes to a reduction in moisture evaporation in the concrete, reducing the drying shrinkage of concrete. In addition, it can be seen that the water absorption of FAC is about $10.3 \%$, which is higher $3.2 \%$ than that of sand. It is also believed to contribute to reducing the drying shrinkage of concrete as indicated in [18]. The authors reported that the higher porosity of the aggregate, the lower the shrinkage of the concrete, especially the autogenous shrinkage because the amount of water absorbed in the aggregate will partially offset the evaporation and contribute a part for internal curing due to water released from these saturated porous aggregate and supply for hydration after 7 days.
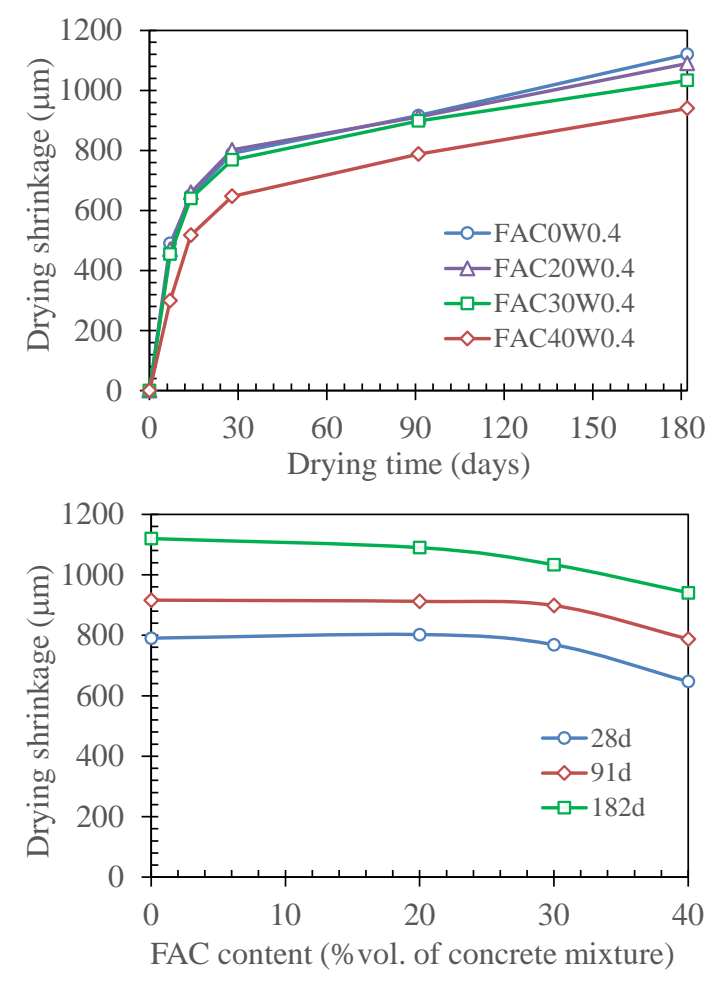

Fig. 2 Effect of FAC content from 0 to $40 \%$ by vol. of on drying shrinkage of FAC HSLWC, W/B $=0.40$ 


\subsection{Effect of W/B Ratio}

Figure 3 clearly shows the influence of the W/B ratio on drying shrinkage of HSLWC when this ratio decreases from $0.6,0.5,0.4$ to 0.35 . The $182-$ day drying shrinkage of concrete containing FAC with W/B of $0.6,0.5,0.4$ to 0.35 was $105,99,84$, and $67 \%$ compared with the reference sample containing $100 \%$ sand (FAC0W40), respectively. It can be seen that the 182-day drying shrinkage of the FAC40W60 mix is very high $(2298 \mu \varepsilon)$ with the W/B ratio of 0.6. Meanwhile, drying shrinkage of the FAC40W35 sample with the W/B ratio of 0.35 is significantly reduced to $765 \mu \varepsilon$. Note that with the same binder content, the volume of the binder pastes increases when increasing the water content of FAC HSLWC mixes. It means that the amount of free water and total porosity in the binder matrix increase. Thus, the water evaporation increases, leading to shrinkage increased when concrete is exposed to the dry environment.
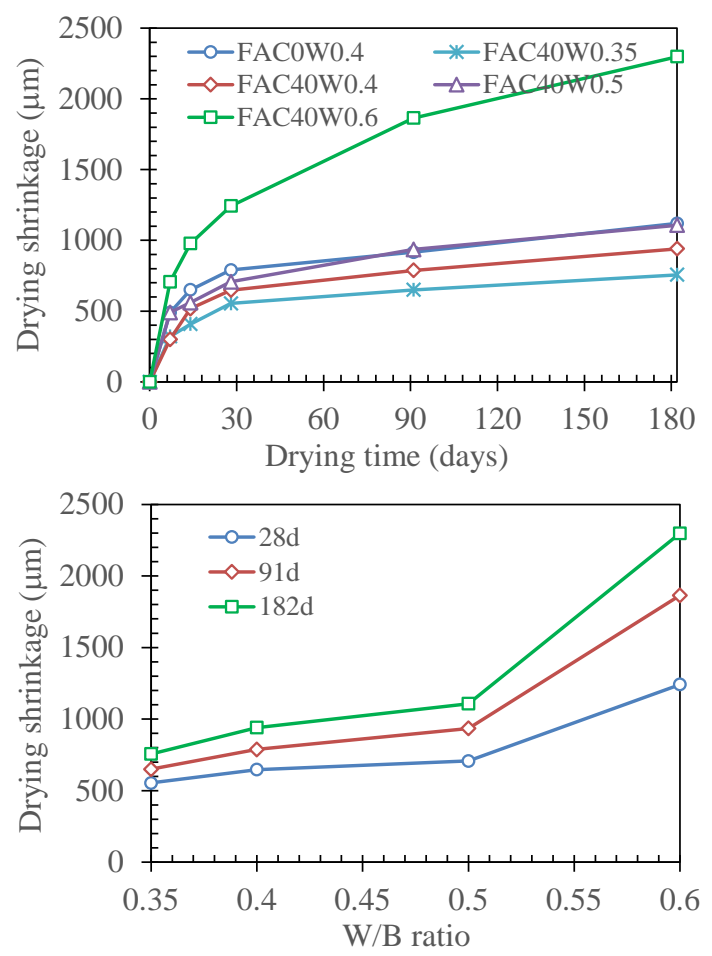

Fig. 3 Effect of W/B on drying shrinkage of FAC HSLWC

\subsection{Effect of Binder Content on Drying Shrinkage}

Figure 4 shows the drying shrinkage of FAC HSLWC with different binder contents of 750, 850, and $950 \mathrm{~kg} / \mathrm{m}^{3}$. The results show that increasing these binder contents increased drying shrinkage of concrete, i.e. 940, 962, and $986 \mu \varepsilon$, respectively. Note that, the binder contents of 750,850 , and $950 \mathrm{~kg} / \mathrm{m}^{3}$ have corresponded amounts of binder paste were 571, 627, and $697 \mathrm{~kg} / \mathrm{m}^{3}$. Thus, the increasing drying shrinkage of concrete, in this case, is caused by the increase of binder and paste contents. This is attributed due to reducing of the FAC content, which is improved that the higher replacement sand by FAC the lower drying shrinkage can be obtained as shown in Section 3.1. The result is similar to the rule of normal concrete as reported by Neville [19]. However, it can also be observed that the increasing rate of drying shrinkage is not significant with an increase in the binder content. The drying shrinkage of these concrete samples was lower, about 16, 14.1, and $12 \%$ than that of the reference samples without FAC (FACOW0.4), respectively.
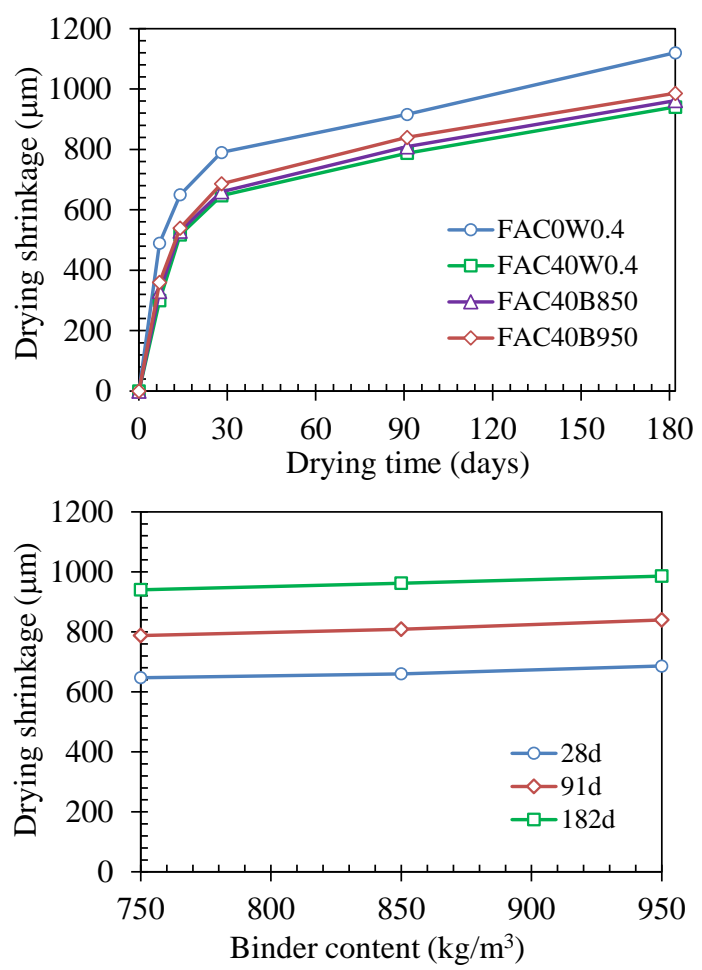

Fig. 4 Effect of binder content on drying shrinkage of FAC HSLWC, W/B $=0.40$

\subsection{Effect of SRA on Drying Shrinkage}

The addition of SRA compensates for the drying shrinkage of concrete, as shown in Fig. 5. The experimental results indicated that the 182-day drying shrinkage of the reference sample without SRA (FAC40W0.4) decreased from 100\% (940 $\mu \varepsilon)$ to $84.2 \%(792 \mu \varepsilon)$ and $90.2 \%(754 \mu \varepsilon)$ compared with the sample containing 2\% SRA (FAC40SRA2.0) and 3\% SRA (FAC40SRA3.0), respectively. It means that the drying shrinkage of concrete reduces accordingly 15.8 and $19.8 \%$.

Besides, compared with the reference sample (FAC0W0.4) without FAC the corresponding reduction is about 29 and $33 \%$ for samples containing 2 and 3\% SRA, respectively. These 
results also demonstrated that the addition of SRA is the most influential factor in reducing shrinkage of FAC HSLWC compared to other factors such as FAC content, W/B ratio, binder content, PP fiber.

The reduction in drying shrinkage with the addition of SRA can be explained by its ability to reduce the surface tension of water in the concrete's pore solution, which reduces the capillary tension of the liquid, causing the formation of capillary pores, and responsible for the shrinkage of cement paste [20]. The effectiveness of using SRA has also been reported to reduce the size of cement paste's pores, reduce air content, and reduce the shrinkage strain when the concrete is subjected to water evaporation (autogenous or drying shrinkage) [11, 21, 22].
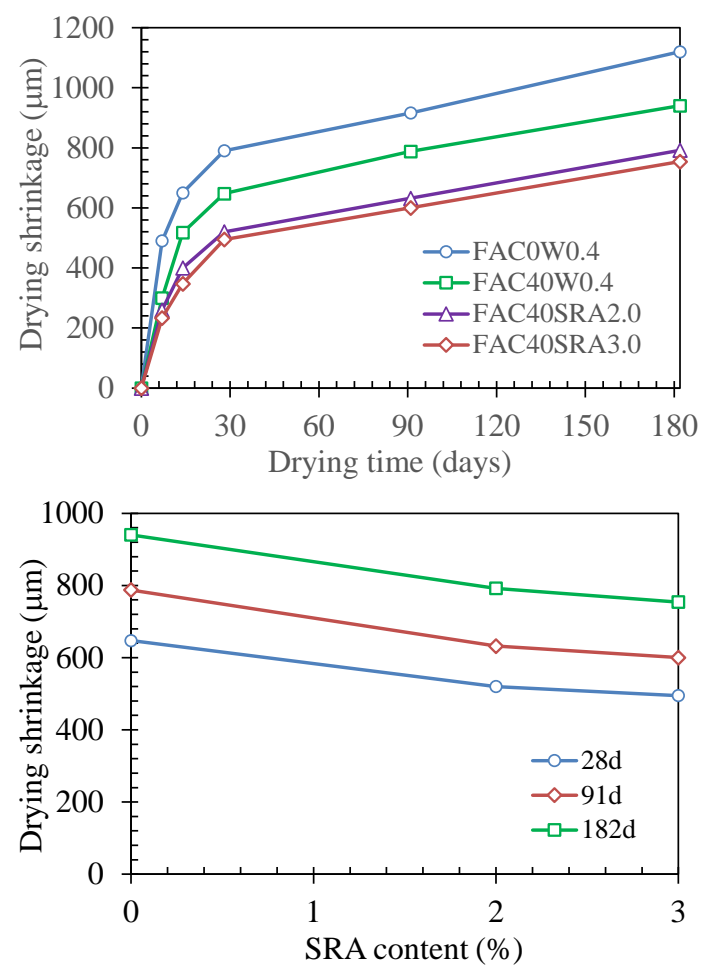

Fig. 5 Effect of SRA content on drying shrinkage of FAC HSLWC, W/B $=0.40$

\subsection{Effect of PP Fiber on Drying Shrinkage}

The effect of PP fiber on drying shrinkage of FAC HSLWC is presented in Fig. 6. The results show that the drying shrinkage of concrete decreases with the PP fiber content from 0 to 0.3 and $0.5 \%$. The 182-day drying shrinkage decreased from $100 \%(940 \mu \varepsilon)$ for the reference specimen without PP fiber (FAC40W0.4) to $95.7 \%(900 \mu \varepsilon)$ and $92.7 \%(872 \mu \varepsilon)$ with the samples containing $0.3 \% \quad$ (FAC40PP20.3) and $0.5 \% \quad \mathrm{PP}$ fiber (FAC4PP0.5) respectively. The results also agree well with the previous studies on the effectiveness of PP fibers in reducing concrete shrinkage [13, 23]. This can be explained mainly because PP fibers act as bridging and stitching small cracks together, resulting in restrain micro-movement in the mortar.
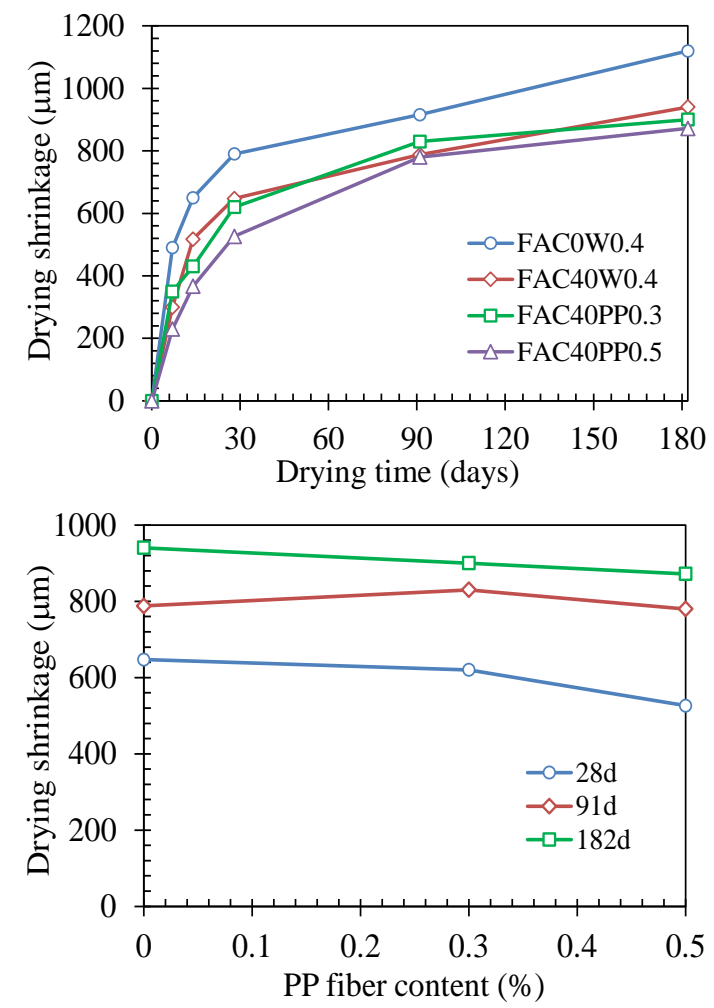

Fig. 6 Effect of PP fiber on drying shrinkage of FAC HSLWC, W/B $=0.40$

\section{CONCLUSIONS}

The influence of factors such as FAC content, W/B ratio, binder content, SRA, and PP fiber on drying shrinkage of fly ash cenosphere highstrength lightweight concrete to the age of 182 days was studied and evaluated in this research. The conclusions can be drawn as follows:

1. The high-strength lightweight concrete using FAC to replace $100 \%$ of sand can be produced, with a W/B ratio of 0.4 , binder content of 750 $\mathrm{kg} / \mathrm{m}^{3}$, the density of $1367 \mathrm{~kg} / \mathrm{m}^{3}$, and reducing 182-day drying shrinkage of concrete of about $26 \%$.

2. The addition of SRA is the most effective way in reducing the drying shrinkage of FAC HSLWC compared with other solutions, i.e. it helps to increase the FAC content, reducing the $\mathrm{W} / \mathrm{B}$ ratio, reducing the binder content, and using PP fiber;

3. The addition of $0.3-0.5 \%$ PP fiber by vol. of the concrete mixture reduces 4.3 to $7.3 \%$ drying shrinkage of the concrete;

4. The drying shrinkage of FAC HSLWC with density from 1367 to $1708 \mathrm{~kg} / \mathrm{m}^{3}$ and the waterto-binder ratio of 0.4 is in the range of 754 to $1090 \mu \varepsilon$, which is more extensive than that of conventional concrete (with coarse aggregates) but lower than that of fine aggregate concrete (without coarse aggregates). 


\section{ACKNOWLEDGMENTS}

This research has been supported by Vietnam Ministry of Science and Technology (Grant No.21/2019/HD-NDT dated 30/12/2019). The financial support from the above organization is gratefully acknowledged.

\section{REFERENCES}

[1] ACI 213R-14: Guide for Structural Lightweight-Aggregate Concrete, 2014, pp.8-9.

[2] Ranjbar, N. and Kuenzel, C., Cenospheres: A review, Fuel, vol. 207, 2017, pp.1-12

[3] Hanif, A., Lu, Z., and Li, Z., Utilization of fly ash cenosphere as lightweight filler in cementbased composites - A review, Construction and Building Materials, vol. 144, 2017, pp.373-384

[4]Bartake, P. P. and Singh, D. N. J. J. o. A. I., Determination of crushing strength of cenospheres, ASTM International, vol. 2, no. 7, 2005, pp.1-9

[5] Liu, F., Wang, J., Qian, X., and Hollingsworth, J., Internal curing of high performance concrete using cenospheres, Cement and Concrete Research, vol. 95, 2017, pp.39-46

[6] Sohel, K. M. A., Liew, J. Y. R., Yan, J. B., Zhang, M. H., and Chia, K. S., Behavior of steel-concretesteel sandwich structures with lightweight cement composite and novel shear connectors, Composite Structures, vol. 94, no. 12, 2012, pp.3500-3509

[7] Montgomery, D. and Diamond, S., The influence of fly ash cenospheres on the details of cracking in fly ash-bearing cement pastes, Cement and Concrete Research, vol. 14, no. 6, 1984, pp.767-775

[8] Losiewicz M., H. D. P., Dews J.S, Olomaiye P., Harris F.C, An investigation ino the properties of micro-phere insulating concrete, Construction and Building Materieals, vol. 10, 1997, pp.583-588

[9] Blanco, F. G. I., P.; Mateos, P.; Ayala, J, Characteristics and properties of lightweight concrete manufactured with cenosheres, Cement and Concrete Research, vol. 30, no. 11, 2000, pp.1715-1722

[10]Huang, X., Ranade, R., Zhang, Q., Ni, W., and Li, V. C., Mechanical and thermal properties of green lightweight engineered cementitious composites, Construction and Building Materials, vol. 48, 2013, pp.954-960

[11]Wang, J.-Y., Chia, K.-S., Liew, J.-Y. R., and Zhang, M.-H., Flexural performance of fiberreinforced ultra lightweight cement composites with low fiber content, Cement and Concrete Composites, vol. 43, 2013, pp.39-47

[12] Chia, K.-S., Liu, X., Liew, J.-Y. R., and Zhang, M.-H., Experimental study on creep and shrinkage of high-performance ultra lightweight cement composite of $60 \mathrm{MPa}$, Structural Engineering and Mechanics, vol. 50, no. 5, 2014, pp.635-652

[13] Zhang, P. and Li, Q.-f., Effect of polypropylene fiber on durability of concrete composite containing fly ash and silica fume, Composites Part B: Engineering, vol. 45, no. 1, 2013, pp.1587-1594

[14] Aly, T., Sanjayan, J. G., and Collins, F., Effect of polypropylene fibers on shrinkage and cracking of concretes, Materials and Structures, vol. 41, no. 10, 2008, pp.1741-1753

[15] Kayali O., H. M. N., Zhu B., Drying shrinkage of fibre-reinforced lightweight aggregate concrete containing fly ash, Cement and Concrete Research, vol. 29, no. 11, 1999, pp.1835-1840

[16] Neville, A. M., Properties of Concrete, The 4th edition.Longman, London, 1995, pp.429-436.

[17] Hanif, A., Lu, Z., Cheng, Y., Diao, S., and Li, Z., Effects of Different Lightweight Functional Fillers for Use in Cementitious Composites, International Journal of Concrete Structures and Materials, vol. 11, no. 1, 2017, pp.99-113

[18] Kohno, K. O., T.; Isikawa, Y.; Sibata, T.; and Mori, H., Effect of Artificial Lightweight Aggregate on Autogenous Shrinkage of Concrete, Cement and Concrete Research, vol. 29, 1999, pp.611-614

[19] A. M. Neville, Properties of Concrete, The 4th edition.Longman, London, 1995, pp.429-436.

[20]Tazawa E., M. S., Influence of cement and admixtures on autogenous shrinkage of cement paste, Cement and Concrete Research, vol. 25, no. 2, 1995, pp.281-287

[21]Rajabipour, F., Sant, G., and Weiss, J., Interactions between shrinkage reducing admixtures (SRA) and cement paste's pore solution, Cement and Concrete Research, vol. 38, no. 5, 2008, pp.606-615

[22] Balogh, A., New admixture combats concrete shrinkage, Concrete Construction, 1996, pp.546-551

[23] Karahan, O. and Atiş, C. D., The durability properties of polypropylene fiber reinforced fly ash concrete, Materials \& Design, vol. 32, no. 2, 2011, pp.1044-1049

Copyright (C) Int. J. of GEOMATE All rights reserved, including making copies unless permission is obtained from the copyright proprietors. 